\title{
Race, food, and borders: Situating migrant struggle in the Okanagan Valley, British Columbia
}

COMMENTARY ON RACE AND

ETHNICITY IN FOOD SYSTEMS WORK

\author{
Elise Hjalmarson ${ }^{a}$ \\ The University of British Columbia \\ Robyn Bunn ${ }^{\mathrm{b}}$ \\ The University of British Columbia \\ Amy Cohen ${ }^{\mathrm{c}}$ \\ Okanagan College \\ Edna Terbasket ${ }^{\mathrm{d}}$ \\ Ki-Low-Na Friendship Society \\ Levi Gahman e* \\ The University of the West Indies
}

Submitted June 15, 2015 / Published online July 30, 2015

Citation: Hjalmarson, E., Bunn, R., Cohen, A., Terbasket, E., \& Gahman, L. (2015). Race, food, and

borders: Situating migrant struggle in the Okanagan Valley, British Columbia. Journal of Agriculture,

Food Systems, and Community Development, 5(4), 77-82. http://dx.doi.org/10.5304/jafscd.2015.054.007

Copyright (C) 2015 by New Leaf Associates, Inc.

\begin{abstract}
Over the past century, the Okanagan Valley's social, economic, and physical landscape has been largely shaped by the region's agricultural industry. Within this landscape migrant farmworkers have an essential role, yet are rendered invisible and remain marginalized. This commentary explores migrants' struggle by looking at the intersections of

Note: In the spirit of collective work, lead authorship is both interchangeable and equally shared.

a Elise Hjalmarson, Master's Candidate, Political Studies, The University of British Columbia, Okanagan; Co-founder, Radical Action with Migrants in Agriculture; elisehjalmarson@gmail.com

b Robyn Bunn, PhD Student, Interdisciplinary Studies, The University of British Columbia, Okanagan; Organizer, Radical Action with Migrants in Agriculture; robynbunn129@gmail.com
\end{abstract}

colonialism, race, borders, and the local food economy. We begin with a historical examination of the racialized nature of the region's agricultural labor force, and also provide an overview of the local food economy. Following this, we outline Canada's Seasonal Agricultural Worker Program (SAWP) and discuss how the SAWP places migrant

c Amy Cohen, Professor of Anthropology, Okanagan College, British Columbia; Co-founder, Radical Action with Migrants in Agriculture; amiecohen@yahoo.ca

${ }^{\mathrm{d}}$ Edna Terbasket, Executive Director, Ki-Low-Na Friendship Society, Kelowna, British Columbia; executivedirector@kfs.bc.ca

e * Corresponding author: Levi Gahman, PhD, Lecturer, Institute for Gender and Development Studies, Department of Geography, The University of the West Indies, St. Augustine Campus; Republic of Trinidad and Tobago; levi.gahman@sta.uwi.edu 
laborers in positions of precarity, often resulting in worker isolation and superexploitation. We then turn to the social conditions migrant workers encounter upon arriving in the Okanagan Valley by describing the institutional discrimination they face, as well as the everyday prejudices and aggressions they endure due to their status of being labeled both "foreign" and "temporary." Next we provide a brief explanation of settler colonialism, the imposition of borders, and the common struggles shared by migrant workers and Aboriginal people. Finally, we offer some recommendations for change that would ameliorate some of the challenges migrant workers experience upon arriving in the Okanagan.

\section{Keywords}

Temporary Foreign Worker Program, Seasonal Agricultural Worker Program, migrant labor, racism, settler colonialism, food systems, Okanagan Valley

\section{The Okanagan Valley, British Columbia: Unceded Syilx Territories}

Within the Okanagan Valley there is an ongoing, yet largely hidden, migrant struggle. This struggle is broadly defined by what is "seen" and what remains "unseen." More specifically, the hypervisibility of mostly white residents and tourists enjoying locally produced food and wine lies in stark contrast to the largely invisible plight of both racialized migrant workers and Aboriginal people. This juxtaposition highlights the diverse yet contradictory cultural landscape of the region, where the politics of food, race, and colonialism are intertwined.

In this commentary, we explore how these complexities have come to be. We do so by providing an intersectional overview of settler colonialism, Canada's Seasonal Agricultural Worker Program (SAWP), and the experiences of racialized migrant workers living in a culture of white privilege. Our discussion is informed primarily by empirical data gathered from formal and informal interviews with Mexican and Caribbean SAWP workers, ethnographic fieldwork undertaken by the authors, and over two years of grassroots community organizing.
In Canada the connection between food and race manifests itself most vividly when looking at settler colonialism's imposition of borders. Considering the lasting effects of settlement on Aboriginal communities, it becomes clear that the Canadian state imposed its borders to eliminate Indigenous people, to accumulate land, and as a way to enable corporations to amass profits (Coulthard, 2014; Hunt, 2014; Razack, 2002). The practice of asserting colonial borders led to forced dislocations of Indigenous inhabitants and the commodification of the Indigenous territories into private properties, some of which are now settler-owned, for-profit orchards, vineyards, and farms. Dispossession, whether it applies to Aboriginal people in Canada who have had their territories expropriated or farmers from different countries who have been displaced and become migrant workers, thus serves as the prime example of the links between colonialism, race, and the current food system (Andrée, Ayres, Bosia, Mássicotte, 2014; Holt-Giménez \& Shattuck, 2011). Accordingly, as this commentary unfolds we (the authors) recognize that the colonial geography we discuss throughout the piece is the unceded Syilx territories of the Okanagan Nation. It is with the acknowledgment of the Syilx people as rightful overseers of the land since time immemorial that we proceed in our overview of food and race in the Okanagan Valley.

\section{A Brief History of Race and Agricultural Labor in the Okanagan Valley}

The Okanagan Valley is well known for its striking landscape, sunny weather, and pleasant temperatures. Located in the south-central interior of British Columbia, it is considered one of BC's most fertile regions. It sits upon a mountainous, pineforested topography scattered with pristine lakes, sandy beaches, vibrant orchards, and manicured vineyards. Due to the region's status as a premier wine producer, it is often referred to as "Napa of the North" and proudly brands itself as a tourist attraction and retirement destination. The region is also heavily marketed as having a trendy food culture, luxurious resort and golf scene, relaxing environment, and bustling overall economy. Today the Okanagan's agricultural sector alone is a billion dollar industry. Despite this, migrant farmworkers 
in the valley, who are at the heart of the agricultural economy, remain invisible.

Over the past century, the Okanagan's agricultural economic base has transitioned from ranches, farms, and orchards to a postsubsistence food economy revolving around wineries and agritourism, as well as food production for both local and global markets (Hessing, 2010). This ongoing historical process has thereby transformed the area into a predominantly "white space" (Aguiar, Tomic, \& Trumper, 2005). Orcharding in particular shaped the pattern of settlement and the ethnic makeup of growing communities. Since the early 1900s, the development of irrigation systems and the accompanying parceling off of lands were conscious efforts made by land-development companies to attract wealthier British (white) immigrants. Orcharding was advertised as a "gentleman's pursuit" in order to entice this class and/or race of immigrants to the "British Garden of Eden" (Demeritt, 1995).

Farmworkers, however, were typically not members of the same demographic of immigrants who were drawn to the Okanagan as farm owners. Early laborers were often from Aboriginal communities or were Japanese or Chinese immigrants (Wong, 1989). Farmworkers were then positioned as necessary but unwanted community members. In 1917 a wartime labor shortage prompted members of the BC Fruit Growers Association (BCFGA) to call for the federal government to allow for the import of indentured Chinese laborers (BCFGA, n.d.). At the time, migration from China was restricted and Chinese immigrants were prohibited from owning land, further marginalizing farmworkers and ensuring that they would not become permanent members of predominantly white communities (Wong, 1989)

Currently, the Okanagan has a thriving agricultural industry for both local and export-oriented products. The tree fruit industry reports revenues of CA $\$ 130$ million each year (BC Tree Fruits, n.d.) and is reliant on migrant farm labor, primarily workers in the SAWP, to continue to be profitable. The local food industry is also central to the billion-dollar tourism sector of the economy, as visitors come to experience the food and wine for which the region is renowned. The social landscape and perceptions of the Okanagan as a "Garden of Eden" is produced through agritourism, the growing wine industry, and an affluent locavore culture, yet the farmworkers (predominantly racialized) who cultivate and harvest the food served to privileged locals and tourists (disproportionately white) are erased from local restaurant and winery scenes. This dependency on migrant labor goes widely unrecognized, as it is undervalued and remains largely unseen by those outside the industry. Thus, despite their invisibility, it is undeniably clear that racialized migrant workers drive the local food economy.

\section{Canada's Seasonal Agricultural Worker Program (SAWP)}

Of the nearly 40,000 migrant agricultural workers legally employed across Canada in 2012, some 30,000 were contracted from Mexico and Caribbean countries through Canada's federal SAWP (Employment and Social Development Canada [ESDC], 2014). The oldest and longest-standing of Canada's temporary migrant worker programs, the SAWP was first conceived in response to grower lobbying in 1966 as a pilot program to meet the labor demands of Ontario's expanding agricultural sector. Since its introduction, the SAWP has grown steadily and attracted global attention for its bilateral approach to the management of circular labor migration, in addition to its collaborative administration in involving industry, government bodies, and the ministries of migrant-sending states. Since British Columbia joined the SAWP in 2004, the number of SAWP workers destined for BC has grown fivefold, from 855 the first year to nearly 5,000 in 2012 (ESDC, 2014), with approximately half being sent to farms in the Okanagan Valley. Today the SAWP is the most commonly utilized of four agricultural streams of the federal Temporary Foreign Worker Program (TFWP) and is a mainstay of Canada's agricultural economy. The program has a reputation as a "model" for the world (Parliament of Canada, 2010).

Despite its popularity with growers and policymakers, as well as migrant workers for whom the program is an essential source of income, the SAWP has been criticized for rendering migrant workers "unfree" (Trumper \& Wong, 2010; Walia, 
2010). This occurs through several specific aspects of the program. First, the SAWP ties workers' visas to a single employer, preventing them from seeking jobs on other farms or outside of agriculture. This results in the segregation of labor by separating "foreign" workers who cannot leave their job from "local" (citizen) workers who can exercise labor mobility. Second, under the SAWP growers are mandated to provide housing for migrant workers, which is typically on-farm. Requiring employers to oversee housing for their labor force is problematic not only because it facilitates increased surveillance of workers, but also because it simultaneously positions growers as migrants' landlords. Third, the SAWP precludes workers from paths to permanent residency, excluding them from legal and political rights and making them vulnerable to deportation if they complain about working or living conditions, or even if they become unable to work due to injury.

This "permanently temporary" status demonstrates that SAWP workers are only valued as laborers and not as citizens, as were other racialized groups throughout the 20th century. All in all, while rejecting the SAWP as a global model for the management of agricultural labor migration, numerous voices have exposed the program's flaws and demonstrated the ways that the SAWP renders "foreign" migrant workers highly precarious, isolated, and superexploitable (Paz Ramirez, 2013; Preibisch, 2012). We now turn to some examples of the conditions that arise for migrant workers in the SAWP.

\section{Racism and Everyday Life: Experiences of SAWP Workers in the Okanagan Valley}

A combination of legal and extralegal mechanisms result in migrant workers' virtual exclusion from the wider communities. Despite the fact that many spend more time in Canada than their "home" countries, they cannot bring their families and are heavily discouraged from forming intimate relationships while in Canada, so that they have nothing to "distract" them from work. SAWP workers' presence in their wider communities is highly regulated and kept to an absolute minimum as they live under the watchful gaze of their employers, conform with extralegal "house rules" (such as curfews and no visitor policies) imposed by many farm owner/landlords, and lack access to transportation. Whether these rules are framed in terms of maintaining productive work forces, protecting permanent jobs for "citizens," or minimizing employers' liability, in practice they combine to create a de facto system of racial segregation.

In addition to being excluded from Canadian society through both legal and extralegal mechanisms, SAWP workers are often targets of everyday acts of racism on farms and in the wider communities. Many cite being assigned less desirable, "dirtier and harder" tasks, or being paid at lower rates, as ways employers treat them differently than Canadian workers. Farm housing is often segregated by country of origin, with the worst accommodations assigned to black workers. Numerous migrant workers from the Caribbean and Mexico recount being followed, or repeatedly questioned, by law enforcement officials both in situations where they are on farm, as well as when they are off the premises simply moving in and about the community.

It is also not uncommon for Mexican men walking along busy roads to be the daily target of racial epithets, or get yelled at by passersby in vehicles to: "Go back to Mexico!" An especially troubling incident occurred one evening when a group of Mexican migrants were at a local pub and a man picked a fight with them, yelling, "go back to the cherry orchard where you belong!" (A. Lopez, personal communication, October 2014). These examples illustrate the aggressions SAWP workers endure in the Okanagan, and demonstrate how being a racialized farmworker, labeled as "foreign," and told "you do not belong here" are integral parts of racist discourse and practice.

\section{Common Struggle and Decolonizing Solidarity: On Becoming "Unsettled'}

Echoing the opening lines of this commentary, we again contend that links between colonial borders, race, and food do exist. As the Okanagan Valley's agricultural economy is operating upon a foundation of land dispossessed from Indigenous people, as well as the superexploitation of migrant workers, we believe any conversation about the region's food system should include the topics of colonialism, capitalism, and racism. We also realize that 
discussions of such systems can often prove to be sensitive and uncomfortable. Despite this, we consider listening to these conversations and becoming "unsettled" by such topics to be necessary parts of decolonizing solidarity (Hunt \& Holmes, 2015).

Engaging in these dialogues will also require an honest admission about what has been (disproportionally) the result of these issues for Aboriginal people and migrant workers; for many it has been isolation, segregation, and, more succinctly, a denial of their dignity. In noting that Aboriginal people and migrant workers experience oppression as a result of racism and ongoing colonialism, we are not contending both groups are homogenous, nor are we suggesting they are affected in exactly the same ways. Rather we are stating that both have been targeted and compromised by colonial borders yet remain resilient in the face of them, and therefore a common struggle exists. In this way, this commentary serves as a reminder to humbly listen to, and committedly struggle with, the Aboriginal people and migrant workers in our local communities, despite the complexities we know will arise in doing so.

As residents of the Okanagan Valley who are troubled by these issues, we would also like to propose a few short- and long-term remedies to the problems touched upon in this piece-specifically the injustice inherent in current Canadian food systems. Ultimately, the racial segregation of our communities, the forced separation of families, and the existence of a two-tier labor force (with one having less access to social, legal, and political rights) are rooted in the policies of illegitimate colonial governments. The only long-term solution to these problems, in our view, is a dismantling of the imposed borders and immigration laws used to adjudicate and enforce belonging and exclusion.

We recognize that decolonization is a longterm project and process, and from some perspectives may even seem impractical; therefore we would also like to suggest some "in the meantime" solutions for some of the most grievous issues. Firstly, SAWP workers' visas should not be tied to a single employer, but like any citizen or permanent resident of Canada, they should be free to change employers for any reason. This would alleviate to some extent the extreme power imbalances currently existing between SAWP workers and farm owners. Secondly, farm owners should not be landlords for their employees. Workers should be paid a fair living wage, one that allows them to freely choose where to reside and not be obligated to live under the housing conditions, surveillance, and arbitrary rules of their employers. Finally, SAWP workers should not have to choose between employment and their families. While many argue that the decision to become a migrant worker and move away from one's family is a personal choice, we also realize the unjust circumstances creating the conditions to do so are inherently societal. Individual decisions to migrate cannot be judged in isolation, nor can they be critiqued outside of the socio-economic situation in which they are made. Thus we believe that the current family-fracturing policy faced by migrant workers is inhumane and must be changed. Spouses and children of SAWP workers should be automatically eligible to come to Canada as visitors, students, or workers.

In sum, when the SAWP was established in 1966 it was conceived as a temporary solution to a short-term labor shortage. Nearly 50 years on, it is clear that the shortage was not temporary and the program has in no way been a "quick fix." While the SAWP serves as an economic lifeline to tens of thousands of migrant farmworkers, it also capitalizes on their precarious circumstances by legislating the inequalities they face and perpetuating the racial discrimination they experience within our food system. In this way, justice for migrant farm labor, as well as Aboriginal people, requires that we cultivate a socially just food system, one not built upon colonial borders rendering certain people (and races) temporary and disposable, but rather one founded upon affording dignity and belonging to all.

\section{References}

Aguiar, L. L. M., Tomic, P., \& Trumper, R. (2005). Work hard, play hard: Selling Kelowna, BC, as yearround playground. The Canadian Geographer/Le Géographe Canadien, 49(2), 123-139. http://dx.doi.org/10.1111/j.0008-3658.2005. $\underline{00084 . x}$ 
Andrée, P., Ayres, J., Bosia, M. J., \& Mássicotte, M.-J. (Eds.). (2014). Globalization and food sovereignty: Global and local change in the new politics of food. Toronto: University of Toronto Press.

British Columbia Fruit Growers Association [BCFGA]. (n.d.) A fruitful century: Wartime conditions, 1914-1918. Retrieved June 2015 from http://www.bcfga.com/ 239/Wartime + Conditions $\% 2 C+1914-1918$

British Columbia Tree Fruits. (n.d.). Our industry. Retrieved June 2015 from http://www.bctree.com/about/our-industry

Coulthard, G. S. (2014). Red skin, white masks: Rejecting the colonial politics of recognition. Minneapolis: University of Minnesota Press.

Demeritt, D. (1995). Visions of agriculture in British Columbia. BC Studies: The British Columbian Quarterly, 108, 29-59. http://ojs.library.ubc.ca/index.php/bcstudies/

Employment and Social Development Canada [ESDC]. (2014). Labour market opinions - Annual statistics. Retrieved from http://www.esdc.gc.ca/ eng/jobs/foreign_workers/lmo_statistics/annualagriculture.shtml

Hessing, M. (2010). After the harvest: Towards a sustainable Okanagan? [Commentary]. BC Studies: The British Columbian Quarterly, 168, 81-94. http://ojs.library.ubc.ca/index.php/bcstudies/

Holt-Giménez, E., \& Shattuck, A. (2011). Food crises, food regimes and food movements: Rumblings of reform or tides of transformation? The Journal of Peasant Studies, 38(1), 109-144. http://dx.doi.org/10.1080/03066150.2010.538578

Hunt, S. E. (2014). Witnessing the colonialscape: Lighting the intimate fires of Indigenous legal pluralism (Doctoral dissertation). Simon Fraser University, Burnaby, British Columbia.

Hunt, S., \& Holmes, C. (2015). Everyday decolonization: Living a decolonizing queer politics. Journal of Lesbian Studies, 19(2), 154-172. http://dx.doi.org/10.1080/10894160.2015.970975

Parliament of Canada. (2010, May 27). House of Parliament, House of Commons Debates, 40th Parliament, 3rd Session. Retrieved from http://www.parl.gc.ca/HousePublications/ Publication.aspx?DocId $=4559699$ \&Language $=\mathrm{E}$

Paz Ramirez, A. G. (2013). Embodying and resisting labour apartheid: Racism and Mexican farm workers in Canada's Seasonal Agricultural Worker Program (Master's thesis). University of British Columbia, Vancouver.

Preibisch, K. (2012). Migrant workers and changing work-place regimes in contemporary agricultural production in Canada. International Journal of Sociology of Agriculture and Food, 19(1), 62-82. http://ijsaf.org/

Razack, S. (Ed.). (2002). Race, space, and the law: Unmapping a white settler society. Toronto: Between the Lines.

Trumper, R., \& Wong, L. L. (2010). Temporary workers in Canada: A national perspective. Canadian Issues, Spring, 83-89.

Walia, H. (2010). Transient servitude: Migrant labour in Canada and the apartheid of citizenship. Race and Class, 52(1), 71-84. http://dx.doi.org/10.1177/0306396810371766

Wong. L. L. (1989). Chinese capitalist migration to Canada: A sociological interpretation and its effect on Canada. Asian and Pacific Migration Journal, 4(4), 465-492. http://dx.doi.org/10.1177/011719689500400401 